\title{
"Functional Outcome of the Results of Locking Compression Plate for the Treatment of Non-United Humeral Shaft Fracture Augmented with Autogenouscancellous Bone Graft: A Study in Pabna Medical College Hospital, Pabna, Bangladesh"
}

\author{
Md. Masudur Rahman ${ }^{1 *}$, Md. Mohiuddin Aslam²
}

${ }^{1}$ Assistant Professor, Department of Orthopaedic Surgery, Pabna Medical College, Pabna, Bangladesh

${ }^{2}$ Assistant Professor, Department of Orthopaedic Surgery, Shaheed Ziaur Rahman Rahman Medical College, Bogura, Banglaesh

DOI: $10.36347 /$ sjams.2020.v08i07.009

| Received: 22.06.2020 | Accepted: 01.07.2020 | Published: 09.07.2020

*Corresponding author: Md. Masudur Rahman

Abstract

Introduction: A fracture bone usually heals by the formation of new bone at the fracture site. Occasionally, only fibrous tissue is formed, when this happens both surgeon \& patient are disappointed. The bone is a specialized form of connective tissue may account for its ability to heal by the formation of new bone. The humerus is a long bone connecting two important joints of upper limb- which has wide range of movement having very little bony stability in shoulder joint and distal elbow joint which is a uni axial hinge joint. Objective: To find out the Functional Outcome Of The Results Of Locking Compression Plate For The Treatment Of Non-United Humeral Shaft Fracture Augmented With Autogenouscancellous Bone Graft. Materials \& Methods: This prospective study of "treatment of nonunion of humeral shaft fracture by locking plate and screws augmented with autogenouscancellous bone grafting" was carried out during the period of $1^{\text {st }}$ December 2014 to 31th May 2016 at Pabna Medical College, Pabna, Bangladesh. Sample size will be calculated by using following statistics $=384$. Purposive sampling (nonrandomized) according to availability of the patients and strictly considering the inclusion and exclusion criteria. Data will be collected with a pre-tested structured questionnaire containing history, clinical examination, laboratory investigations, pre-operative, per-operative, postoperative follow up findings and complications. Observations and Results: This prospective study of treatment of nonunion of humeral shaft fracture by locking plate and screws augmented with autogenouscancellous bone grafting was carried out in 16 patients to find out the common cause of fracture, age and sex incidence and to propose a protocol for treating such cases. Sixteen patients were included in the study group and they were divided into 4 -groups. The mean age was 38.19 with a standard deviation mean $( \pm \mathrm{SD}) 0.04$ years. The age ranged from 28 to 60 years and the maximum number was found in the age group of 30 - 39 years. Motor vehicle accident was the commonest cause of fracture found in $81.25 \%$ cases. Second most common cause was fall from height (12.50\%). Right side involvement was more (62.50\%). Among the affected people ser\Tce holders and shopkeepers were commonest (25\% each), next were businessmen and farmers $(18.75 \%$ each). The mean union time was $16.38(+2.78)$ weeks. Postoperative complications were noticed such as wound infection $(6.25 \%)$ and shoulder pain $(6.25 \%)$. There was no complication (81.25\%). Functional outcome of this treatment was analyzed by Constant and Murley scoring (1999). Excellent functional outcome was found in 5 (31.25\%) cases, good in 9 (56.25\%) cases, fair in $1(6.25 \%)$ case and poor in $1(6.25 \%)$ case. Regarding the final outcome satisfactory result was found in 14 $(87.50 \%)$ cases and unsatisfactory result in $2(12.50 \%)$ cases. Conclusion: Based on the results shown above it is concluded that "treatment of nonunion of humeral shaft fracture by locking plate and screws augmented with autogenouscancellous bone grafting" is an effective modality of treatment for the nonunion of humeral shaft fracture and is especially recommended in osteoporotic bones and elderly patients with compromised bone quality.

Keywords: Per-operative, Postoperative, Complications, autogenouscancellous bone grafting.

Copyright @ 2020: This is an open-access article distributed under the terms of the Creative Commons Attribution license which permits unrestricted use, distribution, and reproduction in any medium for non-commercial use (NonCommercial, or CC-BY-NC) provided the original author and source are credited.

\section{INTRODUCTION}

A fracture bone usually heals by the formation of new bone at the fracture site. Occasionally, only fibrous tissue is formed, when this happens both surgeon \& patient are disappointed. The bone is a specialized form of connective tissue may account for its ability to heal by the formation of new bone [1]. The humerus is a long bone connecting two important joints 
of upper limb- which has wide range of movement having very little bony stability in shoulder joint and distal elbow joint which is a uni axial hinge joint. It is an unpaired bone, the shaft of which is totally covered by a thicker layer of soft tissue. Approximately $10 \%$ of all long bone fractures occur in the humerus. Fracture of the humeral shaft is commonly encountered by the orthopaedic surgeons, accounting for approximately $30 \%$ of all humeral fractures [2]. Both younger and elder people suffer from these fractures. The mechanism of injury is mainly direct trauma, motor vehicle accident, fallfrom height, direct blow and penetrating injury like bullet or sharp object causing transverse or comminuted fractures. Indirect trauma due to fall on out stretched hand, twisting injuries or even violent muscle contraction results spiral or oblique fracture. Treatment of these injuries continue to evolve as advances are made in both non-operative \& operative management [3-5]. Most of the humeral shaft fracture heals with close Method without surgical intervention [6], in certain circumstances when this fracture fails to unite in expected period of time (4-6 months after injury) and then it is called delayed union or non-union [7].The middle third of the bone is the most vulnerable in relation to delayed or non-union. This is because, the main nutrient artery enters the bone very constantly at the function of the middle $\&$ lower thirds or in the lower part of the middle third and the foramina of entry are concentrated in a small area of the distal half of the middle third of the shaft on the medial side of the bone $[8,9]$. Stated that operative treatment is usually indicated for non-union, poly trauma patients, bilateral humeral shaft fracture, floating elbow, fractures with neurovascular complications, segmented fractures, radial nerve palsy after manipulation, pathological fracture, failure to obtain or maintain acceptable alignment after close reduction, associated injury or patient conditions precluding close management, failure to conservative treatment $[10,11,12,13]$. Unfortunately not all the fractures of the humeral shaft in the adults united in a specific time and if not given appropriate treatment the fracture can go on to state of established non-union. When this stage of indolence is reached with sclerosis of the bone ends \& mature fibrous tissues laid down between the fragments, treatments become more difficult. It is then necessary not only to refresh the bone surfaces but also immobilize them as rigidly as possible, which cannot be done by simple plaster cast $\&$ not even by a shoulder Spica [14, 15]. When fractures of the upper extremity are treated, the social and economic status of the patient must be considered. An operation may be justified in preference to the risks of prolonging convalescence, yet union may be possible without surgery if immobilization is continued for 6 to 8 months after injury [16]. Patient often find the hanging cast uncomfortable, tedious and frustrating; they can fell the fragments moving and that is sometimes quite distressing the temptation is to 'do something' and the something usually means an operation [17]. Operative methods of treatment include open reduction and internal fixation by plate \& screws (LCP, DCP), open or close reduction \&internal fixation by intramedullary interlocking nail or semiflexible pins and external fixator $[18,19,20]$. Successful union in 24 of $25(96 \%)$ aseptic non union of the humerus. Rosen, 1990 reported $97 \%$ healing rate with one surgical procedure in 32 humeral non unions treated with dynamic plate and screws [21]. Two series have reported excellent results for treatment of humeral nonunion with compression platting combined with cancellous bone grafting. A recent trend in internal fixation has been a more towards locking compression plating system. With locking compression plating system the locking screws are locked with plate which stabilizes the screws and gives better rigid fixation. The friction between the plate $\&$ bone is less that provides less disturbance of periosteal blood supply [22]. Several new locked plate devices have been developed because researchers suggest plates with attached (locked) screws may provide improved fracture stability \& healing [23]. Locking the screws to the plate mechanically recreates a point of cortical bone contact [24], which may be useful in poor cancellous bone of proximal humerus. Locking compression plates also a have preconfigured shape \& screw direction which may reduce hardware complications. Early clinical results using the locking-humerus, plates have been promising [25]. Locking compression plates provide stable fixation of poor quality bone in patients with delayed union or non-union of the humerus; successful union $\&$ restoration of function are achieved in most patients [26]. Both experimental \& clinical studies with early locking compression plates have shown a lower rate of infection with locking system compared with the standard dynamic compression plate [25]. The existing benefits of the new internal fixator principles are enhanced by the combination in the following respects over other modalities of treatment are- Improvement in angular stability due to locking head screws (even if unicortical), accurate plate contouring is not required, and more options \& greater versatility in fracture management especially fracture with limited bone quality are present. However, these new techniques demand very careful pre-operative planning, especially in the sequence of applying different type of-screws since this process requires a clear understanding of the principles governing each technique. The versatility of the system may increase the risk of application error with disturbance to fracture healing- [27], There are some drawbacks to locking compression plates, locking compression plates are more difficult to remove than standard compression plates, cold welding may occur in which the locking screws heads become affixed to the screws hole,\&cannot be removed from the plate without great difficult. Although hard ware removal is not routinely done many practitioners recommend placing all locking screws by hand rather than on power to avoid cold wielding $[26,28]$. In our hospitals, most of the patient of humeral shaft fractures admitted several weeks after injury after taking some form of conservative treatment 
but fail to unite, with the complained of abnormal mobility, stiff elbow and shoulder. These patients need stable internal fixation by either DCP or LCP for early mobilization of elbow and shoulder. LCP is the recent modification of DCP which can give more stable fixation especially in osteoporotic bone [28].The aim of treatment is to give a good functional limb as early as possible with sound bony union to achieve the best result in the humeral shaft fracture in adults and early return to work, much importance to be given to such factors as early accurate diagnosis, rigid internal fixation of the bone with open reduction \& providing autogenouscancellous bone grafting \& lastly cast immobilization in appropriate position. This study will be included those patients who reported to PMCOrthopaedic Department, Pabna, 12-28 weeks old injuries to the arm with the complain of instability, abnormal mobility in arm, mild to severe pain to the fracture site, stiff shoulder and elbow \& impaired function of the limb. The aim of this study will be to evaluate the result of the internal fixation of non-united humeral shaft fractures by locking compression plate \&screws with autogenouscancellous bone-grafting.

\section{Aims AND OBJECTIVES \\ General objective}

To assess the evaluation of results of locking compression plate for the treatment of non-united humeral shaft fracture augmented with autogenouscancellous bone graft.

\section{Specific objectives}

To assess fracture union time and rate by follow up-both clinically \&radio logically. To evaluate post-operative complication

To assess functional outcome of shoulder \& elbow joints by-modified Constant and Murley score.

\section{Materials \& Methods Study design \\ Prospective interventional study (quasi experimental type)}

\section{Study period}

01/ 12/2014 to 31/05 /2016 (18 Months)

\section{Place of study}

Department of Orthopaedics and Traumatology, Pabna Medical College, Pabna, Bangladesh

\section{Study population}

All patients with history, clinical examination and radiological evaluation suggesting non-united fracture of shaft of humerus attended in Pabna Medical College, Pabna, Bangladesh for treatment.

\section{Sample size}

Sample size will be calculated by using following statistics $=384$

\section{Sampling technique}

Purposive sampling (non-randomized) according to availability of the patients and strictly considering the inclusion and exclusion criteria

\section{Data collection procedure}

Data will be collected with a pre-tested structured questionnaire containing history, clinical examination, laboratory investigations, pre-operative, per-operative, postoperative follow up findings and complications.

\section{Inclusion criteria}

a) Established non-union of shaft of the humerus.

b) Age ( 18 to 60 years)

c) Sex- Both sexes.

d) Site- Diaphyseal fractures of humeral shaft between $3 \mathrm{~cm}$ distal to surgical neck and $5 \mathrm{~cm}$ proximal to the olecranon fossa.

e) Any side affected.

f) Failure of conservative treatment.

\section{Exclusion criteria}

a) Recent fracture.

b) Infected non-union.

c) Pathological fracture.

d) Fracture in children.

e) Persistence of wound.

f) Unstable medical illness.

Study procedure: A questionnaire will be prepared by the researcher considering the key variables like age, sex, presenting symptoms, clinical findings, associated medical conditions, investigations, preoperative findings, outcome of surgery which will be verified by the guide. The data will be collected by the researcher himself. Aims \& objectives, procedures risks and benefits of this treatment were explained to the selected patients. The patients will be encouraged for voluntary participation. They will also be assured about the secrecy of information and records. Then written informed consent will be taken from each patient.

Pre-Operative preparation: Patient will be counseled regarding the treatment procedure with emphasis on the available treatment options along with merits and demerits of each. He/she will be informed about the possible post-operative sequele. Informed written consent will be obtained from each case included in the study. All issues regarding the patient's welfare will be approved by the local ethical committee.

\section{Pre anaesthetic check-up will be done}

Patient will be asked to abstain from oral feeding from 6 hours before operation. Appropriate size of LCP and screws will be selected. 
Antibiotics: All patients will be received prophylactic antibiotic, a third generation cephalosporin (ceftriaxone), one gram i.v. and flucloxacillin $500 \mathrm{mg}$ i.v. at the time of induction of anaesthesia. Post operatively parenteral ceftriaxone will be given 12 hourly and flucloxacillin $500 \mathrm{mg} 6$ hourly for 3 days. After 3 days oral cephalosporin (cefixime 200gm 12 hourly) and flucloxacillin $500 \mathrm{mg}$ will be given for a further weeks or till wound healed.

Positioning of patient: During operation patient will be placed in the supine position and sometimes lateral position after GA. Preparation of the skin: Preparation of the skin will be done by soap washing and using an antiseptic on the skin, such as povidoneiodine solution.

\section{Draping was done}

Surgical procedure: With all aseptic precautions open reduction and internal fixation will be achieved with a standard LCP by anterior Henry approach or posterior approach (for distal third).

Follow-up: At the beginning patients will be followed up at three weeks interval. Thereafter at monthly interval till the fracture union will be achieved. Evaluation of the functional outcome will be achieved at 6 months visit. Six months will be chosen as by that time healing of the fracture would normally have taken place \& functional improvement would have reached to a satisfactory level. This protocol will be changed a little in some particular cases due to failure of attending the schedule or other causes. The patients will be also advised to attend the OPD or contact personally if any problem regarding the treatment occurred. Pendulum shoulder exercise will be started after 2 weeks. Long arm back slab will be removed after 3 weeks and were allowed to move the elbow joint. All data analysis windows 16.0 Version

\section{ObServations And Results}

This prospective study of treatment of nonunion of humeral shaft fracture by locking plate and screws augmented with autogenouscancellous bone grafting was carried out in 16 patients to find out the common cause of fracture, age and sex incidence and to propose a protocol for treating such cases. Sixteen patients were included in the study group and they were divided into 4-groups. The mean age was 38.19 with a standard deviation mean $( \pm \mathrm{SD}) 0.04$ years. The age ranged from 28 to 60 years and the maximum number was found in the age group of 30 - 39 years. The age distribution is shown in [Table I].
Table-I: Age distribution of the patients $(n=16)$

\begin{tabular}{|l|c|c|}
\hline Age in years & Number & Percentage \\
\hline$<30$ & 1 & 6.25 \\
\hline $30-39$ & 8 & 50.00 \\
\hline $40-49$ & 4 & 25.00 \\
\hline$>50$ & 3 & 18.75 \\
\hline Mean ^SD & & $38.19 \pm 10.04$ \\
\hline Range & & $(28-60)$ \\
\hline
\end{tabular}

Table-II: Occupational distribution of patients $(\mathrm{n}=16)$

\begin{tabular}{|l|c|c|}
\hline Occupation & Number & Percentage \\
\hline Serviceman & 4 & 25.00 \\
\hline Businessman & 3 & 18.75 \\
\hline Farmer & 3 & 18.75 \\
\hline Shopkeeper & 4 & 25.00 \\
\hline Housewife & 2 & 12.50 \\
\hline
\end{tabular}

Most $(25.0 \%)$ of the patients were service holder and shopkeeper $(25.0 \%), 18.75^{\circ} \mathrm{o}$ were businessman, $18.75 \%$ were farmer and $12.5 \%$ were house wife. "heresults are shown in [Table 2].

Table III: Mean duration of injury of the patients $(n=16)$

\begin{tabular}{|l|l|}
\hline \multicolumn{1}{|c|}{$\begin{array}{c}\text { Duration of injury } \\
\text { (months) }\end{array}$} & Months \\
\hline Mean =SD & $15.38 \pm 3.91$ \\
\hline Range & $(9-20)$ \\
\hline
\end{tabular}

The following table shows the mean duration of injury of the patients was 15.38 monthswith a SD of \pm 3.91 months and the minimum injury duration was 9 months and maximum was 20 months.

Table-IV: Post-operative hospital stay $(n=16)$

\begin{tabular}{|c|c|}
\hline Hospital stay (days) & Days \\
\hline Mean+SD & $4.81 \pm 1.22$ \\
\hline Range & $(3-6)$ \\
\hline
\end{tabular}

The following table shows the average hospital stay of the patients postoperatively. The mean duration of hospital stay was 4.81 days with a SD of 11 days. The maximum and minimum hospital stay was 6 and 3 days respectively.

Table-V: Time of union by radiological evaluation $(n=16)$

\begin{tabular}{|l|l|}
\hline $\begin{array}{c}\text { Radiological evaluation Time of } \\
\text { union }\end{array}$ & Weeks \\
\hline McanrSD & $16.38 \pm 2.78$ \\
\hline Range & $(13-24)$ \\
\hline
\end{tabular}


Radiologically all cases were found to be united and the mean time of presence of union was $16.38 \pm 2.78$ weeks and the maximum and minimum time needed for union were 24 to 13 weeks respectively.

Table-VI: Distribution of patients by post-operative complications $(\mathbf{n}=16)$

\begin{tabular}{|l|c|c|}
\hline $\begin{array}{c}\text { Post-operative } \\
\text { complications }\end{array}$ & Number & Percentage \\
\hline Infection & 1 & 6.25 \\
\hline Loosening of the screw & 0 & 0.00 \\
\hline Shoulder pain & 1 & 6.25 \\
\hline No complication & 13 & 81.25 \\
\hline
\end{tabular}

Most $(81.25 \%)$ of the cases did not have any complication. One patient developed infection and one patient had shoulder pain.

\section{DisCUSSION}

When a humerus fracture fails to unite in 3 to 4 months, it is termed as delayed and if union is delayed and arrested beyond 6 to 8 months, it is nonunion Rosen [29]. Nonunion is established when minimum of 9 months has elapsed since injury and the fracture shows no visible progressive signs of healing for 3 months [30]. Though a number of treatment methods have been documented none of the method seems to be superior to others. Orthopaedic surgeons in several countries contributed to the foundations mat led to the concepts, techniques and instruments used today. Various methods of surgical treatment are known, such as, fixation by plate and screws and bone grafts, intramedullary nails, intramedullary interlocking nails with bone grafts, inlay and onlaytibial grafts with bone pegs or .bone screws, dual ribialonlay grafts dual fibular onlay grafts, cerclage wire, external fixators, llizarov technique. A recent trend in internal fixation has been a more toward locking plating system. Specific advantage of locking plating system includes 1. Stable rigid fixation, 2. Direct reduction, 3. Less periosteal vascular disturbance. Twenty-one cases of humeral nonunion after the failure of locked humeral nails [31, 32]. The study revealed mat open reduction and internal fixation with plating and bone grafting was successful in nine of nine cases and exchange nailing was successful in four often cases. Ramchandersiwach [33], their studies of treating displaced proximal humeral fracture in elderly patients with osteoporosis by locking plate \& screws of 25 patients (12 males \& 13 females) with $28 \%$, excellent outcome, $64 \%$ good functional outcome $\& 8 \%$ had moderate outcome. All fractures united with an; union time of 18 weeks. The humenis is often osteoporotic when nonunion occurs. It becomes difficult to ngid fixation in terms of loosening of screws. There is always tendency to bowing of humerus in its fracture at middle third. Hence there is always 2 feilure of union. By using locking plate \& screws in nonunion of humeral shaft osteoporotic bone it gives better rigid fixation \& chance of loosening. At Pabna Medical College, Pabna the treatment of humeral shaft nonunion by locking plate $\&$ screws with autogenouscancellous bone grafting has gained acceptance in the recent years. This prospective study was carried out during the period from July 2014 to June 2016 at Pabna Medical College, Pabna, Bangladesh, to find out the result of locking plate and screws with; cancellous bone grafting in the non-union of fracture shaft of humerus. A total number of 16 patients were included in this study. All the patients were iy locking plate \& screws augmented with autogenouscancellous bone grafting. Follow up time was 6 months \& maximum 18 months. In this study, age ranges from 28 to 60 years. Hie mean age incidence was 38.19 years. The high incidence in young adult age group points to higher rate of mobility as well as social violence in this age group. Male population in this study constitutes 14 cases $(87.5 \%)$ while the female's $p$ remaining 2 cases $(12.5 \%)$. Observed a male predominance $19^{\wedge}$ Ivhile Wright, showed males to made up 55.55\% and $60 \%$ [34, 35, 36]. Malesr Vig'themajoj Aorking force of our society and are thus more consistently exposed to external environment which probably accounts for this predominance. Motor vehicle accidents were found to be the most common causative factor in this study $81.25 \%$. Christensen [4], Ring et al. [31], observed motor vehicle accidents as the major reason for humeral shaft fractures occupying $50 \%$ and $40 \%$ respectively [37, 38, 39-42]. Second common cause was fall from a height counting $12.50 \%$. In this study right side was affected more $(62.5 \%)$ than left side $(37.5 \%)$. Ring [31], found $66.76 \%$ of the cases with left humeral fractures in his series. In 4 cases, there were associated injuries, 2 had soft tissue injuries, one had ipsilateral fracture shaft of femur, and one had radial nerve injury. Among the 16 cases, 2 of them were treated by open reduction and internal fixation with $D C P$, one treated initially with external fixator, the rest of them were treated conservatively with U slab, long arm back slab. Post-operative hospital stay is one of the important parts of this study. In this series minimum 3 days and maximum 6 days. Mean post-operative stay 4.8 (+1.22) days. Longer hospital stay was required for patients having postoperative infection and other complication. Union time of fracture in this series was minimum 13 weeks and maximum 24 weeks. Mean $16.38(+2.78)$ weeks. In the study of Robinson et al. [31], men time of union 18 weeks (8-96 weeks) but 7 patients required treatment for delayed union. In the study of Habernek and Orthner [10], average union time was 2 months. In this series postoperative infection (Superficial wound infection) developed in 1 patient $(6.25 \%)$ who was controlled by regular dressing and sensitive antibiotic. Shoulder pain in $1(6.25 \%)$ case. In the study of Habernek and Orthner [10], there was no infection in 19 cases and no rotator cuff lesion, in my study infection rate was $6.25 \%$. In this study 5 cases (31.25\%) had excellent functional outcome according to Constant and Murleyscoring, 9 cases (56.25\%) had good, 1 case $(6.25 \%)$ had fair outcome and 1 case 
$(6.25 \%)$ had poor outcome. In this series there was excellent result in 5 cases $(31.25 \%)$, good in 9 cases $(56.25 \%)$, fair in 1 case $(6.25 \%)$ and poor in 1 case $(6.25 \%)$. In this study overall a satisfactory result was found in $14(87.50 \%)$ cases and unsatisfactory in $(12.50 \%)$ cases.

\section{Conclusion}

Based on the results shown above it is concluded that "treatment of nonunion of humeral shaft fracture by locking plate and screws augmented with autogenouscancellous bone grafting" is an effective modality of treatment for the nonunion of humeral shaft fracture and is especially recommended in osteoporotic bones and elderly patients with compromised bone quality.

\section{REFFERENCE}

1. Brumback RJ, Bosse MJ, Poka A, Burgess AR. Intramedullary stabilization of humeral shaft fractures in patients with multiple traumas. JBJS. 1986 Sep 1;68(7):960-70.

2. BRASHEAR HR. Diagnosis and prevention of non-union. JBJS. 1965 Jan 1;47(1):174-8.

3. Carroll SE. A study of the nutrient foramina of the humeral diaphysis. The Journal of bone and joint surgery. British volume. 1963 Feb;45(1):176-81.

4. Christensen NO. 7976. Kuntscher intramedullary reaming and nail fixation for nonunion of the humerus. Din Orthop. 116: 222-225.

5. Crenshaw AH. 'Fractures of the shoulder, arm and forearm', in Canale ST (ed), Campbell's Operative Orthopaedics, Vol. 3, $10^{\text {th }}$ ed, Mosby Inc., St. Louise. 2003; 3004-3013.

6. Epps $\mathrm{CH}$ Jr. 'Nonunion of the humerus', in Bassett FH (ed), Instructional course lecture, volume XXXVII, American Academy of Orthopaedic Surgeons.1988: 161-166.

7. Esterhai JL, Brighton CT, Heppenstall RB, Thrower A. Nonunion of the humerus. dinOrthop.1986; 211: 228-234.

8. Foster RJ, Dixon JG, Bach AW, Appleyard RW, Green TM. Internal fixation of fractures and nonunions of the humeral shaft. Indications and results in a multi-center study. The Journal of bone and joint surgery. American volume. 1985 Jul;67(6):857-64.

9. Healy WL, White GM, Mick CA, Brooker JR AF, Weiland AJ. Nonunion of the humeral shaft. Clinical Orthopaedics and Related Research®. 1987 Jun 1;219:206-13.

10. Habernek H, Orthner E. A locking nail for fractures of the humerus. The Journal of Bone and Joint Surgery. British volume. 1991 Jul;73(4):651-3.

11. Haque A. Management of humeral shaft fracture by antegrade ${ }^{\mathrm{v}}$ mtramedullary interlocking nail at N1TOR. MS Thesis, BSMMU, Dhaka, Bangladesh.2004.
12. Ingman AM, Waters DA. Locked intramedullary nailing of humeral shaft fractures. Implant design, surgical technique, and clinical results. The Journal of bone and joint surgery. British volume. 1994 Jan;76(1):23-9.

13. Jupiter JB. Complex non-union of the humeral diaphysis. Treatment with a medial approach, an anterior plate, and a vascularized fibular graft. The Journal of bone and joint surgery. American volume. 1990 Jun;72(5):701-7.

14. Klenerman L. Fractures of the shaft of the humerus. The Journal of Bone and Joint Surgery. British volume. 1966 Feb;48(1):105-11.

15. Laing PG. The arterial supply of the adult humerus. J Bone Joint Surgery. 1956; 38-A: 1105-1116.

16. Crenshaw AH, Canale ST, Daugherty K, Campbell WC. Campbell's operative orthopaedics. Mosby Year Book; 1992.

17. Mast JW, Spiegel PG, Harvey Jr JP, Harrison C. Fractures of the humeral shaft: a retrospective study of 240 adult fractures. Clinical orthopaedics and related research. 1975 Oct 1(112):254-62.

18. Modabber MR, Jupiter JB. Operative management of diaphyseal fractures of the humerus. Plate versus nail. Clinical orthopaedics and related research. 1998 Feb(347):93-104.

19. Muller ME, Thomas RJ. Treatment of non-union in fractures of long bones. Clinical Orthopaedics and Related Research (1976-2007). 1979 Jan $1 ; 138: 141-53$

20. Murray WR, Lucas DB, Inman VT. Treatment of non-union of fractures of the long bones by the two-plate method. JBJS. 1964 Jul 1;46(5):1027-48.

21. Netter FLI. 'Upper limb ${ }^{1}$, in Atlas of human anatomy, Novartis, New Jersey.1997; 395-410.

22. Saha AC, Ahmed R, Hossain MA, Ghosh AL. Evaluation of Results of Fixation of Nonunion of Fracture Shaft of Humerus by Locking Plate and Screws Augmented by Autogenous Cancellous Bone Graft. The Journal of Bangladesh Orthopaedic Society (JBOS). 2008:23.

23. Pritchett JW. Delayed union of humeral shaft fractures treated by closed flexible intramedullary nailing. The Journal of bone and joint surgery. British volume. 1985 Nov;67(5):715-8.

24. Ray RD, Sankaran B, Fetrow K. Delayed union and nonunion of fractures, Instructional Course Lecture, Vol XXXXVI, American Academy of Orthopaedic Surgeons.1964: 627-643

25. Ring D, Jupiter JB, Quintero J, Sanders RA, Marti RK. Atrophic ununited diaphyseal fractures of the humerus with a bony defect: treatment by waveplate osteosynthesis. The Journal of bone and joint surgery. British volume. 2000 Aug;82(6):867-71.

26. Ring D, Perey BH, Jupiter JB. The functional outcome of operative treatment of ununited fractures of the humeral diaphysis in older patients. JBJS. 1999 Feb 1;81(2):177-90.

27. Rosen H. The treatment of nonunions and pseudarthroses of the humeral shaft. The 
Orthopedic Clinics of North America. 1990 Oct;21(4):725-42.

28. Rosen H. Compression treatment of long bone pseudarthroses. Clinical orthopaedics and related research. 1979(138):154-66.

29. Robinson CM, Bell KM, Court-Brown CM, McQueen MM. Locked nailing of humeral shaft fractures. Experience in Edinburgh over a two-year period. The Journal of bone and joint surgery. British volume. 1992 Jul;74(4):558-62.

30. Ring D. Ununited fractures of the humerus, Harvard orthopaedic Journal.2008.

31. Sarmiento A, Zagorski JB, Zych GA, Latta LL, Capps CA. Functional bracing for the treatment of fractures of the humeral diaphysis. JBJS. $2000 \mathrm{Apr}$ $1 ; 82(4): 478$.

32. Swanson TV, Gustilo RB, Kyle RF, Templeman DC. Fracture of the humeral shaft. Gustilo RB, Kyle RF, Templeman DC. Fractures and dislocations, editors. St. Louis, Mosby. 1993:36586.

33. Siwach R, Singh R, Rohilla RK, Kadian VS, Sangwan SS, Dhanda M. Internal fixation of proximal humeral fractures with locking proximal humeral plate (LPHP) in elderly patients with osteoporosis. Journal of Orthopaedics and Traumatology. 2008 Sep;9(3):149-53.

34. Templeman DC, Schmidt AH. Management of humeral shaft fractures CME. 1'On-lineI Release date: December 20, 2001. Available from: http://www.medscape.eom/viewprograrn/l

50

(Accessed 9 January 2005).

35. Trotter DH, Dobozi WI. Nonunion of the humerus: rigid fixation, bone grafting, and adjunctive bone cement. Clinical orthopaedics and related research. 1986 Mar(204):162-8.

36. Urist MR, Mazet Jr R, McLean FC. The pathogenesis and treatment of delayed union and non-union: a survey of eighty-five ununited fractures of the shaft of the tibia and one hundred control cases with similar injuries. JBJS. 1954 Oct $1 ; 36(5): 931-80$

37. Whitson RO. Relation of the radial nerve to the shaft of the humerus. JBJS. 1954 Jan 1;36(1):85-8.

38. Williams PL, Warwick R, Dyson M, Bannister LH. Gray's Anatomy, Churchill Livingstone. Edinburgh-London-Melbourne-New York. 1989.

39. Wright TW. Treatment of humeral diaphyseal nonunions in patients with severely compromised bone. Journal of the Southern Orthopaedic Association. 1997;6(1):1.

40. Zuckerman JD, Koval KJ. Fractures of the shaft of the humerus. Rockwood and Green's Fractures in Adults, $4^{\mathrm{a}}$ ed. Philadelphia: Lippincott-Raven Publishers. 1996:1025.

41. Owsley KC, Gorczyca JT. Displacement/screw cutout after open reduction and locked plate fixation of humeral fractures. Jbjs. 2008 Feb $1 ; 90(2): 233-40$ 